\section{Perfil das gestantes infectadas pelo HIV atendidas em pré-natal de alto risco de referência de Belo Horizonte}

\section{Profile of HIV-infected pregnant women at a reference prenatal care service in Belo Horizonte}

\author{
Roberta Maia de Castro Romanelli 1 \\ Fabiana Maria Kakehasi 2 \\ Maria do Carmo Teatini Tavares 3 \\ Victor Hugo Melo 4 \\ Lucia Horta Figueiredo Goulart 5 \\ Regina Amélia Lopes Pessoa Aguiar 6 \\ Jorge Andrade Pinto 7
}

\begin{abstract}
Objectives: identify HIV infected pregnant women in a referral center and investigate characteristics related to infection and parity.

Methods: a cross-sectional study comprising all HIV infected women treated at the High Risk Prenatal Care in the Hospital das Clinicas da Universidade Federal de Minas Gerais, in 2004. Demographic data, HIV epidemiology infection and obstetrical history were collected. For statistical analysis SPSS 12.0 was used.

Results: eighty five women median aged 29.1 and 90 pregnancies were followed-up. In 55 pregnancies $(61.1 \%)$ women had prior information of the infection. Sixty four $(71.1 \%)$ informed they lived together. Probably they all acquired HIV in heterosexual relations. Fifty four (60\%) were diagnosed during one of the pregnancies. The global pregnancies median was 3.5, and 1.71 following diagnosis. Patients with prior diagnosis had a higher pregnancy median as compared to those who were diagnosed during their pregnancies $(p=0.002)$. Eighty six pregnant women made use of anti-retroviral medication, $56.7 \%$ through therapeutic indication. No vertical transmission cases were determined.

Conclusions: new pregnancies in HIV infected women are not rare notwithstanding contraceptive resources offered. Therefore, further investigations are necessary to identify what difficulties not previously approached they have during routine medical assistance.
\end{abstract}

Key words Pregnancy, Parity, Women, Diagnosis, HIV

\section{Resumo}

Objetivos: identificar gestantes infectadas pelo HIV em centro de referência e investigar características referentes à infecção e paridade.

Métodos: estudo transversal, que abrangeu toda a população de gestantes infectadas pelo HIV assistidas no Pré-Natal de Alto Risco do Hospital das Clínicas da Universidade Federal de Minas Gerais, em 2004. Foram coletados dados demográficos, epidemiologia da infecção pelo HIV e história obstétrica. Para análise estatística foi utilizado o SPSS 12.0.

Resultados: foram identificadas 85 mulheres com média de idade de 29,1 anos e 90 gestações. Em 55 gestações $(61,1 \%)$, as mulheres tinham conhecimento prévio da infecção. Sessenta e quatro $(71,1 \%)$ informavam união estável. Provavelmente, todas adquiriram o HIV em relações heterossexuais. Cinqüenta e quatro (60\%) tiveram o diagnóstico durante alguma gravidez. A média global de gestações foi 3,5, sendo 1,71 após o diagnóstico. Pacientes com diagnóstico prévio apresentaram maior média de gestações, em relação àquelas com diagnóstico na gestação estudada $(p=0,002)$. Oitenta e seis gestantes usaram anti-retroviral, sendo $56,7 \%$ por indicação terapêutica. Não foram verificados casos de transmissão vertical.

Conclusões: novas gestações em mulheres infectadas pelo HIV não são raras, apesar dos recursos de contracepção oferecidos. Assim, outras investigações são necessárias para a identificar suas dificuldades não abordadas durante a assistência médica de rotina.

Palavras-chave Gravidez, Paridade, Mulheres, Diagnóstico, HIV 


\section{Introdução}

Os seis primeiros casos relatados de infecção pelo HIV em mulheres datam de 1981, nos Estados Unidos. ${ }^{1}$ Ao final de 2005, dados da Joint United Nations Programme on HIV/AIDS 2 estimaram que 40,3 milhões de pessoas eram infectadas, sendo mais de 17,5 milhões de mulheres $(43,4 \%)$. No Brasil, até junho de 2005 haviam sido notificados 370.499 casos de infecção pelo HIV/AIDS, sendo 118.520 mulheres $(31,9 \%){ }^{3}$

No início da epidemia, o número de casos notificados era maior em homens, sendo $24: 1$ a proporção de casos masculinos para os femininos. Atualmente, a proporção entre homens e mulheres com AIDS é de 1,4:1.3 Dados do Ministério da Saúde revelam que a incidência de casos no período de 2000 e 2001 foi maior em mulheres na faixa etária de 13 a 30 anos, excedendo a infecção em homens (0,8: 1 e 0,6: 1, respectivamente). ${ }^{4} \mathrm{~A}$ heterossexualização é uma das características mais marcantes da epidemia do HIV e o número de mulheres infectadas continua a crescer principalmente entre aquelas com relação estável.5-7

Assim, a preocupação com a transmissão vertical tornou-se grande prioridade, pois a maioria dos casos de infecção pelo HIV em crianças ocorre por essa via.5,8 A utilização de zidovudina (AZT) definida pelo protocolo Pediatric Clinical Trials Group 076 (PACTG 076) demonstrou a redução da transmissão do vírus da mãe para o filho em quase $70 \%$ dos casos. 9 A seguir, passou-se a utilizar associação de anti-retrovirais (ARV) em esquema tríplice, e recomendar a via de parto, de acordo com a viremia plasmática, para menor acometimento fetal. Após o nascimento, a amamentação não é permitida e a criança recebe fórmula láctea, além de AZT oral. Quando todas as recomendações são seguidas, a transmissão vertical chega a taxas de 1 a $2 \% .10-12$

Visando a melhoria da assistência à mulher infectada, o Projeto Nascer ${ }^{13}$ passou a recomendar triagem com sorologia anti-HIV para toda gestante durante o pré-natal, possibilitando o diagnóstico da infecção e a profilaxia da transmissão vertical. Assim, a maioria das mulheres infectadas é identificada durante uma gestação ou no momento do parto, situações especiais devido ao significado da maternidade. No entanto, observa-se que em torno de 38 a $48 \%$ das gestantes ainda chegam às maternidades sem resultado da sorologia anti-HIV do pré-natal e necessitam teste rápido no momento do parto, o que pode impedir que todas as ações para prevenção da transmissão vertical sejam realizadas. 14,15 Ressaltase que as atuais "Recomendações para Profilaxia da
Transmissão Vertical e Terapia Anti-retroviral em Gestantes do Ministério da Saúde ${ }^{10}$ preconiza que, se possível, a sorologia deva ser repetida no terceiro trimestre de gestação.

A assistência a essa população tem como principal objetivo evitar o acometimento do feto e do recém-nascido, sem priorizar outras necessidades específicas da mulher infectada, como a contracepção. Conforme recomendado pela Política Nacional de Atenção Integral a Saúde da Mulher, 16 todas as mulheres devem ser assistidas de forma integral e adequada às suas necessidades.

Portanto, este estudo teve como objetivo caracterizar as gestantes infectadas pelo HIV do serviço, para identificar possíveis fatores relacionados às gestações recorrentes nessa população, permitindo o planejamento de ações necessárias que favoreçam a assistência.

\section{Métodos}

Trata-se de estudo transversal descritivo que incluiu todas as gestantes infectadas pelo HIV assistidas no Pré-Natal de Alto Risco (PNAR) do Ambulatório Carlos Chagas do Hospital das Clínicas (HC) da Universidade Federal de Minas Gerais (UFMG) no ano de 2004, localizado em Belo Horizonte, Minas Gerais, Brasil. Esse estudo faz parte de uma pesquisa mais abrangente sobre mulheres não primíparas que engravidaram após o diagnóstico da infecção pelo HIV.

A listagem das pacientes atendidas no PNAR era gerada semanalmente. Cada gestação foi considerada um novo caso, uma vez que algumas mulheres tornaram a ficar grávidas durante o período de estudo. As pacientes foram atendidas por equipe multidisciplinar, constituída pelos obstetras, enfermeiras e pediatras do Grupo Materno-Infantil de AIDS da Faculdade de Medicina da UFMG. No parto, foram encaminhadas para a maternidade Otto Cirne, do HC da UFMG. O seguimento ambulatorial dessas mulheres e seus filhos foi realizado pelos membros do próprio grupo, por um período mínimo de um ano a um ano e meio, após realização de duas cargas virais indetectáveis da criança e um teste ELISA anti-HIV negativo.

Os dados foram colhidos durante o próprio atendimento ou por meio do prontuário médico. Obtiveram-se informações pessoais (idade, estado civil, escolaridade, profissão), de moradia (número de pessoas e cômodos para dormir na residência), sobre a infecção pelo HIV (forma de transmissão, momento do diagnóstico, status sorológico do 
parceiro, classificação, uso de ARV, carga viral e CD4 no momento do parto) e sobre a história obstétrica (número de gestações e abortos, número de gestações após o diagnóstico e tipo de parto). Pela dificuldade de obter dados referentes à renda salarial, as condições socioeconômicas foram consideradas com base na escolaridade, profissão, número de cômodos para dormir e pessoas que moram no mesmo domicílio.

Para análise estatística foi utilizado o Statistical Package for Scientific Science (SPSS) versão 12.0. Em análise univariada, foram obtidos dados percentuais, de comparação de proporções (utilizando-se o teste qui-quadrado) e comparação de médias (utilizando o teste $t$ de Student).

O estudo foi aprovado pelo Comitê de Ética em Pesquisa (COEP) da UFMG (333/04). Não houve intervenções nas condutas médicas ou coleta de exames além dos necessários na rotina assistencial. Para garantir a confidencialidade foi mantido sigilo sobre a identificação das pacientes e sobre as informações obtidas e apenas os pesquisadores responsáveis tiveram acesso aos dados.

\section{Resultados}

Foram identificadas 85 mulheres com 90 gestações. As gestantes estudadas eram adultas jovens, com faixa etária entre 20 e 41 anos, e média de 29,1 anos. Em média, moravam quatro pessoas na mesma residência, com dois cômodos para dormir. No entanto, observou-se até 15 moradores na mesma casa e, na maioria das vezes, havia apenas um ou dois cômodos para dormir. Quanto à escolaridade, $64,4 \%$ informaram ter interrompido seus estudos antes de completar o primeiro grau e $25,6 \%$ antes de completar o segundo grau. Seis mulheres eram analfabetas.

Verificou-se também que $55(61,1 \%)$ delas se definiram como trabalhadoras do lar. Em 38,9\% dos casos foram também relatadas atividades como doméstica ou faxineira, babá e três profissionais do sexo. Considerando o estado civil, em 61 casos $(67,8 \%)$ as mulheres definiram-se com relação estável. Ressalta-se que 24 eram solteiras e duas divorciadas. A caracterização demográfica das pacientes encontra-se na Tabela 1.

Cinqüenta e cinco pacientes $(61,1 \%)$ receberam o diagnóstico da infecção previamente à gravidez em questão. Outros 35 casos $(38,9 \%)$ tinham sido diagnosticados no último pré-natal. No entanto, na maioria das vezes $(60 \%)$ o conhecimento da infecção pelo HIV ocorreu em algum pré-natal ou mesmo no
Tabela 1

Características demográficas das gestantes infectadas pelo HIV ( $N=90)$ atendidas no Ambulatório Carlos Chagas. Belo Horizonte, 2004.

\begin{tabular}{lcc}
\hline Características maternas & Média & Mediana \\
\hline Idade & 29,1 & 29 \\
Pessoas que moram na casa & 4,3 & 4 \\
Cômodos para dormir na casa & 2,1 & 2 \\
\hline & Número de pacientes & $\%$ \\
\hline Estado civil & & \\
Casada ou união estável & 64 & 71,1 \\
Solteira & 24 & 26,7 \\
Divorciada & 2 & 2,2 \\
Escolaridade & & \\
Analfabeta & 6 & 6,7 \\
Elementar & 58 & 64,4 \\
Médio & 23 & 25,6 \\
Não informado & 3 & 3,3 \\
Trabalho & & 81,1 \\
Do lar & 55 & 30,0 \\
Doméstico & 8 & \\
Outro & 27 & \\
\hline
\end{tabular}

Tabela 2

Momento do diagnóstico das gestantes infectadas pelo HIV ( $\mathrm{N}=90)$, atendidas no Ambulatório Carlos Chagas. Belo Horizonte, 2004.

\begin{tabular}{lcc}
\hline Momento do diagnóstico & Número de pacientes & $\%$ \\
\hline Gestação atual & 35 & 38,9 \\
Gestação anterior & 16 & 17,8 \\
Parto anterior & 3 & 3,3 \\
Manifestações clínicas da mulher & 18 & 20,0 \\
Manifestações clínicas do parceiro & 12 & 13,3 \\
Manifestações clínicas do filho & 6 & 6,7 \\
Total & 90 & 100,0 \\
\hline
\end{tabular}

momento do parto, através de teste rápido, referindose a 54 mulheres (Tabela 2).

Em todos os casos, a provável fonte de infecção foi heterossexual. No entanto, apenas 40 dos parceiros tinham o status sorológico conhecido, sendo 22 com sorologia positiva e dezoito não-infectados. De acordo com a classificação do Center of Diseases Control and Prevention (CDC), 17 a maioria das mulheres era assintomática, com média de viremia plasmática de 1840,04 cópias/ml e de linfócitos T CD4+ 
Tabela 3

Características da infecção pelo HIV $(\mathrm{N}=90)$ em gestantes atendidas no Ambulatório Carlos Chagas. Belo Horizonte, 2004.

\begin{tabular}{lcc}
\hline Características maternas & Número de pacientes & $\%$ \\
\hline $\begin{array}{l}\text { Status sorológico do parceiro } \\
\text { Infectado }\end{array}$ & 21 & 23,3 \\
Não-infectado & 18 & 20,0 \\
Ignorado & 51 & 56,7 \\
Classificação & & \\
Leve/moderada (A ou B/ 1ou 2) & 65 & 72,2 \\
Avançada (Categorias C ou 3) & 25 & 27,8 \\
ARV & & \\
Profilático & 39 & 43,3 \\
Terapêutico & 51 & 56,7 \\
\hline & & Média \\
\hline Carga viral no parto & 1840,04 & 29,45 \\
Logarítimo da carga viral no parto & 1,44 & 0,88 \\
Percentual de CD4 no parto & 497,49 & 450 \\
\hline
\end{tabular}

\section{Tabela 4}

Esquemas de anti-retrovirais utilizados pelas gestantes infectadas pelo HIV $(\mathrm{N}=90)$ atendidas no Ambulatório Carlos Chagas. Belo Horizonte, 2004.

\begin{tabular}{lcc}
\hline Anti-retrovirais & Pacientes & $\%$ \\
\hline Esquema tríplice com Inibidor de Protease & 50 & 55,6 \\
Esquema tríplice com Não Análogo & 26 & 28,9 \\
AZT (zidovudina) & 10 & 11,1 \\
Terapia de resgate & 2 & 2,2 \\
Não usou & 2 & 2,2 \\
Total & 90 & 100,0 \\
\hline
\end{tabular}

\section{Tabela 5}

Número de gestações após o diagnóstico da infecção pelo HIV ( $\mathrm{N}=55)$, entre as gestantes atendidas no Ambulatório Carlos Chagas. Belo Horizonte, 2004.

\begin{tabular}{lcc}
\hline Gestações & Número de pacientes & $\%$ \\
\hline 1 & 37 & 67,3 \\
2 & 6 & 10,9 \\
3 & 8 & 14,6 \\
4 ou mais & 4 & 7,2 \\
Total & 55 & 100,0 \\
\hline
\end{tabular}

de 497,49 células/mm3. Apenas 25 mulheres $(27,8 \%)$ tinham doença avançada, definida com categoria clínica $\mathrm{C}$ ou categoria imunológica 3. Os dados referentes à doença materna estão na Tabela 3.

Verificou-se que $56,7 \%$ das gestantes receberam ARV por indicação terapêutica e $43,3 \%$ para profilaxia da transmissão vertical. Duas mulheres não usaram os medicamentos, apesar da prescrição, segundo avaliação médica e farmacêutica. $\mathrm{Na}$ maioria dos casos $(84,5 \%)$ era utilizado ARV em esquema tríplice. Os principais regimes prescritos são apresentados na Tabela 4.

Quando foram comparados o grupo de mulheres com diagnóstico prévio àquelas com diagnóstico na gestação em estudo, não houve diferença estatística quanto à média de idade $(p=0,14)$, à classificação de base da doença $(p=0,60)$, à média de carga viral $(p=0,27)$, ao logaritmo da carga viral $(p=0,37)$ e à contagem de linfócitos T CD4+ $(p=0,59)$, realizados no momento do parto. Apenas a diferença do percentual de linfócitos T CD4+ apresentou tendência à diferença com significância entre os grupos ( $p=0,05)$, mas a média dos dois grupos apresentava-se acima de $25 \%$ ( $31,8 \%$ e $25,4 \%$, respectivamente).

O número de gestações variou de um a oito com média de 3,5. Vinte e seis mulheres tiveram entre um e três abortamentos (média 0,46). A média de gestações entre as 55 mulheres com diagnóstico prévio da infecção foi de 4,0. Apesar da maioria $(67,6 \%)$ delas ter apresentado apenas uma gravidez após conhecimento de sua infecção (média 1,71), foram identificadas pacientes com duas a sete gestações após diagnóstico (Tabela 5). Ressalta-se ainda que cinco delas engravidaram novamente no mesmo ano do nascimento do filho anterior (2004), sendo que duas dessas evoluíram para abortamento.

Ao final do ano de 2004, 71 (78,9\%) pacientes já haviam evoluído para parto e 17 (18,9\%) permaneceram em acompanhamento pré-natal, com parto em 2005. Ao todo, três delas evoluíram para abortamento. Verificou-se que 27,6\% dos partos ocorridos foram por via vaginal e $72,4 \%$ foram cesáreas, sendo a prevenção da transmissão vertical a principal indicação do parto cirúrgico. Não houve caso de transmissão vertical do HIV identificado no grupo estudado.

\section{Discussão}

Atualmente a epidemia da infecção pelo HIV atinge camadas sociais cada vez mais pobres.5-7 $\mathrm{Na}$ amostra incluída nesse estudo, verificaram-se precárias 
condições de moradia, de escolaridade e atividade profissional restrita. Em geral, elas eram provenientes de camadas sociais menos favorecidas, sendo que muitas pacientes necessitam auxílio como valetransporte e cesta-básica, muitas vezes oferecidos pelo próprio serviço para que pudessem comparecer às consultas.

Pode-se dizer que a heterossexualização da doença decorreu, especialmente, da infecção da mulher pelo parceiro infectado, que adquire o HIV em relações extraconjugais ou através do uso de drogas intravenosas. ${ }^{18-20}$

Neste estudo, verificou-se que todas as mulheres relatavam provável transmissão sexual. Entretanto, muitas vezes os parceiros não realizavam a sorologia anti-HIV, quando o diagnóstico era feito através da mulher. Freqüentemente, verificou-se nos prontuários a ausência de registro sobre o atendimento do parceiro. Como se trata de uma doença sexualmente transmissível é recomendado que se faça o aconselhamento pré e pós-teste do paciente e de seus parceiros, com solicitação de sorologia e encaminhamento para serviço de referência. ${ }^{21} \mathrm{Na}$ maioria dos casos $(55,6 \%)$, não se conhecia o status do parceiro, sendo que apenas 22 sabiam-se infectados e 18 tinham sorologia negativa.

Demonstrou-se também que, em $60 \%$ dos casos, a mulher teve o seu diagnóstico durante a triagem sorológica do pré-natal ou no momento do parto. Sendo a gravidez momento de mudanças físicas e emocionais para a realização da mulher,22 ao gerar uma criança na vigência da infecção pelo HIV, elas devem lidar com outros conflitos, além daqueles inerentes ao processo da gestação. Ressalta-se, portanto, a revelação diagnóstica de uma doença estigmatizante que, freqüentemente, refere à morte; a revelação diagnóstica para o parceiro, que faz emergir conflitos do casal, culpabilidade e problemas relacionados à sexualidade; e a possibilidade de um filho infectado, motivo de grande sofrimento para as mães. 23

Por outro lado, oferecer a sorologia anti-HIV para essas pacientes é dever do profissional e direito da paciente, conforme determinado pelas recomendações do Projeto Nascer ${ }^{13}$ e do Programa de Humanização no Pré-natal e Nascimento. 24 As Recomendações para Profilaxia da Transmissão Vertical do HIV e Terapia Anti-retroviral em Gestantes 10 têm como principal objetivo a redução da transmissão vertical do vírus, sendo o pré-natal uma oportunidade para o diagnóstico dessas mulheres.11,12,16,24 Além dos procedimentos técnicos recomendados, a sua assistência demanda cuidados especiais para que a abordagem do diagnóstico, em um momento bastante especial, seja bem conduzida.

No período do estudo foi verificada a ocorrência de 90 gestações em pacientes infectadas pelo HIV. Considerando a atual gravidez, o número médio de gestações dessas mulheres foi de 3,5 , acima da média brasileira de 2,1 nascidos vivos por mulher. 24 Excluindo os casos de abortos, a diferença entre o grupo estudado e a população brasileira é menor, com média de 2,8 nascimentos, pouco acima dos dados do Instituto Brasileiro de Geografia e Estatística (IBGE). ${ }^{25}$ No entanto, as pacientes com diagnóstico prévio à gestação atual, tiveram maior número de gestações (média de 4,04), com diferença estatística em relação à média daquelas com diagnóstico na gestação em estudo (média 2,66).

Porém a experiência da maternidade para essas mulheres é contraditória, pois a possibilidade de gerar e criar um filhos se contrapõem ao medo da transmissão vertical e ao estigma da infecção, muitas vezes diagnosticada durante a gestação.26,27 Não se questiona o direito à maternidade dessas mulheres, mas se elas estão tendo o direito à prevenção e ao planejamento de sua vida reprodutiva.28,29 Observase que, mesmo com toda a estrutura de um serviço terciário e todos os recursos oferecidos para essas pacientes, como atendimento multidisciplinar, medicamentos anti-retrovirais e orientações sobre contracepção, elas tornaram a engravidar. Toda a assistência é facilitada quando elas estão grávidas. Por outro lado, questiona-se se elas tiveram acesso aos métodos contraceptivos, já que o planejamento familiar é função da assistência primária. 16 Não se abordaram aqui questões referentes ao desejo de uma nova gestação mas, provavelmente, a ocorrência de gestação não planejada não está relacionada apenas a questões biomédicas da assistência, sendo influenciada especialmente pelas precárias condições socioeconômicas e pelas desigualdades nas relações de gênero. 6,7,26-30

Ressalta-se que esses dados fazem parte de um estudo de pesquisa qualitativa para uma abordagem mais ampla das questões envolvidas na ocorrência de novas gestações dessas mulheres. Com os dados obtidos, buscou-se contribuir para a compreensão do processo de saúde reprodutiva, no qual estão inseridas as pacientes infectadas pelo HIV, para planejar a melhoria do atendimento oferecido. Para isso, os serviços especializados devem ser estruturados para garantir os direitos reprodutivos dessa população, com acesso às demandas contraceptivas, ao seguimento puerperal e ao planejamento familiar. 


\section{Referências}

1. Guinan ME, Hardy A. Epidemiology of AIDS in woman in the United States: 1981 through 1986. JAMA. 1987; 257 : 2039-42.

2. UNAIDS (Joint United Nations Programme on HIV/AIDS). AIDS epidemic update: December, 2005. Available from: URL: www.unaids.org. [2006 Feb 16].

3. Chequer P. Dados epidemiológicos de AIDS. Bol Epidemiol AIDS. 2005; Ano II: 24-34.

4. Teixeira PR. Análise das tabelas e gráficos do Boletim Epidemiológico AIDS [editorial]. Bol Epidemiol AIDS. 2001/2002; Ano XV: 3-6.

5. Dhalia C, Barreira D, Castilho EA. A AIDS no Brasil: situação e tendências. Bol Epidemiol AIDS. 1999/2000; Ano XIII [on line]. Disponível em URL: http://www.aids.gov. br/udtv/boletim\%5dez99\%5Fjun00/sumario\%5Fjun00.htm [2003 Mar 22]

6. Bastos FI, Szwarcwald CL. AIDS e pauperização: principais conceitos e evidências empíricas. Cad Saúde Pública. 2000; 16 (Supl 1): 65-76.

7. Parker R, Camargo Jr KR. Pobreza e HIV/AIDS: aspectos antropológicos e sociológicos. Cad Saúde Pública. 2000; 16 (Supl 1): 89-102.

8. Brito AM, Souza JL, Luna CF, Dourado I. Tendência da transmissão vertical de AIDS após terapia anti-retroviral no Brasil. Cad Saúde Pública. 2006; 40 (Supl): 18-21.

9. Connor EM, Sperling SR, Gelber R, Kiselev P, Scott G, O'Sullivan MJ, VanDyke R, Bey M, Shearer W, Jacobson R, Jimenez E, O'Neill E, Bazin B, Delfraissy JF, Culnane M, Coombs R, Elkins M, Moye J, Stratton P, Balslay J. For the pediatric AIDS Clinical Trials Group Protocol 076 Study Group. Reduction of maternal-infant transmission of human immunodeficiency virus type 1 with zidovudine treatment. N Engl J Med. 1994; 331: 1173-80.

10. Ministério da Saúde. Coordenação Nacional de DST/AIDS. Recomendações para profilaxia da transmissão vertical e terapia anti-retroviral em gestantes. Brasília (DF); 2006. Disponível em URL: http://www.aids.gov.br/data/documents/storedDocuments/\%7BB8EF5DAF-23AE-4891AD36-1903553A3174\%7D/\%7BECC34B93-6A8A-4F99B8D4-88890AD7EB0C\%7D/ ConsensoGestantes2006_ 05julho2006.pdf [2006 set 6].

11. Minkoff H. Human immunodeficiency virus infection in pregnancy. Obst Gynecol. 2003; 101: 797-810.

12. Cohan D. Perinatal HIV: special considerations. International AIDS Society. Top HIV Med. 2003; 11: 200-13.

13. Ministério da Saúde. Projeto Nascer. Portaria 2104 de 19 de Novembro de 2002: institui, no âmbito do Sistema Único de Saúde - SUS -, o Projeto Nascer-Maternidades e dá outras providências. Diário Oficial da União. [DOU] 2002 nov 21; Secção 1: 25.

14. Morimura MCR, Mendes MDC, Souza AI, Alencar LCA. Freqüência de testagem rápida para o HIV durante a admissão para o parto em puérperas no Instituto Materno Infantil Prof. Fernando Figueira, IMIP. Rev Bras Saúde Matern Infantil. 2006; 6 (Supl 1): S69-S76.

15. Ministério da Saúde. Monitoraids. Brasília (DF); dezembro de 2004. Disponível em: www.aids.gov.brm\&abibliotecamonitoraids.pdf\#search $=\% 22$ monitoraids $\% 202004 \% 20$ pdf $\% 22$ [2006 ago 6].
16. Ministério da Saúde. Política Nacional de Atenção Integral a Saúde da Mulher. Princípios e diretrizes. Brasília (DF); 2004. Disponível em URL: <http://dtr2001.saude.gov.br /bvs/publicacoes/politica_nac_atencao_mulher.pdf> [2005 jul 4].

17. CDC (Center of Diseases Control and Prevention). Revised classification system of human immunodeficiency virus infection in children less than 13 years of age. MMWR. 1992; 41: 1-10.

18. Alves MFP. Sexualidade e prevenção de DST/AIDS: representações sociais dos homens rurais de um município da zona da mata pernambucana, Brasil. Cad Saúde Pública. 2003; 19 (Supl 2): S429-S39.

19. Monteiro S. Qual prevenção? AIDS, sexualidade e gênero em uma favela carioca. Rio de Janeiro: FIOCRUZ; 2002.

20. Rede Nacional Feminista da Saúde e Direitos Reprodutivos. Saúde da mulher e direitos reprodutivos: dossiês. São Paulo; 2001.

21. Ministério da Saúde. Programa Nacional de DST/AIDS. Manual de controle das doenças sexualmente transmissíveis DST. Brasília (DF); 1999.

22. Maldonado MT. Psicopatologia da gravidez. 15. ed. São Paulo: Saraiva; 2000.

23. Rede Paulista de Mulheres Vivendo com HIV/AIDS. Grupo de Incentivo à Vida. Brasil, Ministério da Saúde. Coordenação Nacional de DST/AIDS. Fios de vida: tecendo o feminino em tempos de AIDS, 2003. Disponível em URL: www.aids.gov.br/final/biblioteca/fios_vid/ fois1.htm [2004 out 15].

24. Ministério da Saúde. Portaria 569/GM. 1o de Junho de 2000: institui o Programa de Humanização no Pré-Natal e Nascimento (PHPN). Diário Oficial da União. [DOU] 2000 jun 8; Seção 1: 4.

25. IBGE (Instituto Brasileiro de Geografia e Estatística). Censo demográfico 2000. Disponível em URL: http://www.ibge.gov.br/home/presidencia/noticias/26122003censofecundhtml.shtm [2005 jul 3].

26. Doyal L, Anderson J. My fear is to fall in love again... How HIV-positive African womem survive in London. Soc Sci Med. 2005; 60: 1729-38.

27. Kirshenbaum SB, Hirky AE, Correale J, Goldstein RB, Johnson MO, Rotheram MJ, Ehrhardt AA. Throwing the dice: pregnancy decision-making among HIV-positive women in four US cities. Perspect Sex Reprod Health. 2004; 36: 106-13.

28. Oliveira LA, Junior IF. Demandas reprodutivas e a assistência às pessoas vivendo com HIV/AIDS: limites e possibilidades no contexto dos serviços de saúde especializados. Cad Saúde Pública. 2003; 19: 315-23.

29. Knauth DR, Barbosa RM, Hopkins K. Between personal wishes and medical prescription: mode of delivery and post-partum sterilization among woman with HIV in Brasil. Reprod Health Matters. 2003; 11: 113-21.

30. Castro A, Farmer P. Understading and adressing AIDSrelated stigma: from antrophological theory to clinical practices. Am J Public Health 2005; 95: 53-9.

Recebido em 25 de janeiro de 2005

Versão final apresentada em 7 de junho de 2006

Aprovado em 28 de agosto de 2006 